\title{
Hepatoprotective effects of Rubus coreanus miquel concentrates on liver injuries induced by carbon tetrachloride in rats
}

\author{
Hyun-Jung Chae ${ }^{1 *}$, Jung-Eun Yim ${ }^{2 *}$, Kyung-Ah $\mathrm{Kim}^{3}$ and Jong-Hee Chyun ${ }^{1 \S}$ \\ ${ }^{1}$ Department of Food and Nutrition, Inha University, 100 Inha-ro, Namgu, Inchon 402-751, Korea \\ ${ }^{2}$ Department of Food and Nutrition, Changwon National University, Gyeongnam 641-773, Korea \\ ${ }^{3}$ Department of Pharmacy, Kyung Hee University, Seoul 130-701, Korea
}

\begin{abstract}
As well-being foods pursuing healthy life are becoming popular, interest in Rubus coreanus Miquel (RCM) fruit, a type of Korean blackberry, is increasing due to its medicinal actions including protecting the liver, brightening the eyes, and alleviating diabetes. This study was carried out to evaluate the hepatoprotective effects of RCM concentrates on liver injuries induced by carbon tetrachloride $\left(\mathrm{CCl}_{4}\right)$ in rats. RCM, produced in June $\sim$ July 2008 at Chunbook, Gochang (South Korea), was finely mashed. The seeds were removed and the juices were condensed. Thirty-two Sprague-Dawley rats were divided into four groups according to treatment: normal (eight rats), $\mathrm{CCl}_{4}, 1 \% \mathrm{RCM}$, and $2 \% \mathrm{RCM}$. Experimental diets were provided to the experimental animals for 4 weeks. We measure total cholesterol, high density lipoprotein-cholesterol (HDL-C), aspartate amino transferase (AST), alanine amino transferase (ALT), and alkaline phosphatase (ALP) levels. Part of the livers was isolated for histopathological evaluation, and analyzed for lipid peroxide (TBARS), superoxide dismutase (SOD) and liver proteins. The activities of serum AST, ALT, and ALP were elevated following $\mathrm{CCl}_{4}$ administration. Levels of hepatic TBARS were also significantly increased in the $\mathrm{CCl}_{4}$ groups. However, hepatic TBARS levels and the activities of serum enzymes were markedly reduced by supplementation with the RCM concentrates $(P<0.05)$. Hepatic SOD activity increased in the RCM concentrates group versus $\mathrm{CCl}_{4}$ groups. Histopathological examination revealed massive necrosis in the centrilobular area and degenerative changes caused by $\mathrm{CCl}_{4}$ were ameliorated by dietary supplementation with $\mathrm{RCM}$ concentrates. These results suggest that $\mathrm{RCM}$ concentrates have hepatoprotective effects and may improve the symptoms of liver injuries.
\end{abstract}

Key Words: Rubus coreanus Miquel, carbon tetrachloride, hepatoprotective effects

\section{Introduction}

The liver is seriously threatened by many factors such as irregular diet, stress, drug overdose, viruses, toxic reagents, and alcohol. In particular, the consumption of alcohol is increasing excessively as social relationships become complicated and diversified. Alcohol linked to various forms of liver disease such as fatty liver, hepatitis, liver cirrhosis, and liver cancer. Impaired liver functions and liver diseases can be fatal and represent an important threat since these conditions are difficult to treat [1].

With increased awareness of liver health, development and studies of related drugs are ongoing, and interest in identifying foods that improve liver function is also increasing. Silymarin, an agent that improves the liver and bowels, was developed from the fruit of Silybum rarianum, a member of the chrysanthemum family [2]. A more recently developed drug, dimethyl-4,4'bimethyloxy-5,6,5',6'-dimethylene-dioxydiphenyl-2,2'-bicarbox ylate (DDB), is known to combat hepatotoxicity [3]. The synthesis of these compounds is similar to that of Schisandrin B, a derivative of Schisandra chinensis.

As the popularity of foods believed to have positive pharmacological effects on human health increases, more attention has been given to traditional Korean foods [4]. Recently, interest in Rubus coreanus Miquel (RCM), a type of Korean blackberry, is growing as this fruit is known to have beneficial medical actions [5-7]. RCM is also expected to help treat chronic disease due to its anti-cancer and antioxidant functions, and improve liver function given its polyphenol, organic acid, and vitamin $\mathrm{C}$ content [5-7].

RCM grows wild in sunny locations in valleys, at the foot of mountains, and arid lands at altitudes $50 \sim 1,000 \mathrm{~m}$ in South Korea [8]. RCM has been used to help protect the liver, brighten the eyes, and alleviate diabetes [9]. RCM supplementation enhanced antioxidant capacity in healthy Korean men [10].

In a study of bioactive components of RCM, four kinds of hydrolysable tannins and four kinds of flavonoids have been

\footnotetext{
This work was supported by Inha University.

${ }^{\S}$ Corresponding Author: Jong-Hee Chyun, Tel. 82-32-860-8123, Fax. 82-32-862-8120, Email. jhchyun@inha.ac.kr

* These two authors contributed equally to this study.

Received:October 24, 2012, Revised: October 31, 2013, Accepted: November 7, 2013

(c) 2014 The Korean Nutrition Society and the Korean Society of Community Nutrition

This is an Open Access article distributed under the terms of the Creative Commons Attribution Non-Commercial License (http://creativecommons.org/licenses/by-nc/3.0/)

which permits unrestricted non-commercial use, distribution, and reproduction in any medium, provided the original work is properly cited.
} 
isolated and identified [11]. Sanguiin H-4 and H-6, hydrolyzed tannins have also been identified in a study of the tannin compounds in this fruit [12], and other studies on raspberry terpenoids have been conducted $[13,14]$. Raspberries contain components such as nigaichigoside F1, F2, suavis simoside, and new glycosides of coreanoside F1. Since coreanoside F1 exists only in raspberries, this compound can be used for identification purposes [15]. Coreanoside F1 is a dimeric triterpene glycosyl ester believed to be one of the major components of herbal medicines that quench thirst and protect the liver [9]. In a study of RCM bioactivity, the density of polyphenols was high in both the fruit and leaf [16]. In another report of RCM antioxidant activity, levels of electron donation by a,a'-diphenyl- $\beta$-picrylhydrazyl (DPPH) were described as high [10]. DPPH was also was found to have high nitrite clearance and superoxide dismutase (SOD) activities. Due to these bioactive components, RCM has been reported to affect immune function, possess antioxidant activity, suppress type B hepatitis viral infection, and control weight [17]. However, research on the ability of RCM to help protect the liver and improve liver function is insufficient.

In this study, we investigated the ability of RCM to protect against liver injury and enhance hepatic function against $\mathrm{CCl}_{4}$-induced hepatic damage in male Sprague-Dawley (SD) rats. The activity of aspartate amino transferase (AST), alanine amino transferase (ALT), alkaline phosphatase (ALP), blood lipids (triglycerides, total cholesterol, HDL-cholesterol), hepatic lipid peroxide, and activity of superoxide dismutase (SOD) in liver tissue were measured in order to analyze the hepatoprotective effects of RCM. The extent of liver damage was also examined through histopathological observation.

\section{Materials and Methods}

\section{Plant materials and preparation of RCM}

RCM produced at Gochang, Chunbook-do, South Korea was purchased from Osung Food Co. The fruit was finely mashed and the seeds were removed with a juicer (Hanil juice extractor, HEX-9100B, Seoul). The juice was condensed and stored in a freezer until use. The yield of RCM concentrate from fresh RCM fruit was $26 \%$. The water contents of RCM concentrate was $60.79 \%$.

\section{Experimental animals}

Seven-week-old male SD rats (Hyundai Bio, South Korea) were used for the animal experiment. The animals were randomly divided into four groups (eight rats per group) according to treatment: normal, $\mathrm{CCl}_{4}, 1 \% \mathrm{RCM}$, and $2 \% \mathrm{RCM}$. The rats were individually housed in wire-mesh cages in a room maintained at $20 \pm 2{ }^{\circ} \mathrm{C}$ and $50 \pm 5 \%$ relative humidity (Auto Control System, SS-2000). To induce liver toxicity, carbon tetrachloride $(1 \mathrm{~mL} / \mathrm{kg}$,
$\mathrm{CCl}_{4}$ :olive oil $=1: 1, \mathrm{v} / \mathrm{v}$ ) was injected into the abdominal cavity on the first day of the experiment, and every 3 days twice a week from that day. An identical volume of olive oil was injected into normal group rats. Experimental diets were provided to the animals for 4 weeks. Each group of rats was then sacrificed, and blood and livers were collected for analysis. The study protocol for all animal experiments was approved by the Institutional Animal Care and Use Committee of Changwon National University (2013-2).

\section{Experimental diet}

The control diet composition was based on purified AIN-76 (American Institute of Nutrition, 1977), and the experimental diets were supplemented with $1 \%$ or $2 \%$ condensed RCM juice (Table 1). A gel-type agar diet, consisting of a diet : agar : water ratio of $490 \mathrm{~g}: 10 \mathrm{~g}: 1000 \mathrm{~g}$, was produced. New experimental diets were fed every day in the form of gel by 50 55 g (20 $\mathrm{g}$ in the form of powder), and ion-free water was freely provided [18].

\section{Measurement of blood lipids}

Experimental animals were starved for 12 hours before sacrifice. The rats were anesthetized with ethyl ether, the abdomen was opened, and blood was collected from the hearts. Serum was stored frozen at $-70^{\circ} \mathrm{C}$ before the analysis. Serum triglyceride (TG), total cholesterol (TC), and high density lipoproteincholesterol (HDL-C) levels were measured with an enzymatic

Table 1. Composition ( $\mathrm{g} / 100 \mathrm{~g}$ diet) of the experimental diets

\begin{tabular}{|c|c|c|c|c|}
\hline Ingredient & $\mathrm{CON}$ & $\mathrm{CCl}_{4}$ & $1 \% \mathrm{RCM}$ & $2 \% \mathrm{RCM}$ \\
\hline Casein & 20 & 20 & 20 & 20 \\
\hline DL-methionine & 0.3 & 0.3 & 0.3 & 0.3 \\
\hline Corn oil & 5 & 5 & 5 & 5 \\
\hline Corn starch & 49 & 49 & 49 & 49 \\
\hline Sucrose & 16 & 16 & 16 & 16 \\
\hline a-cellulose & 5 & 5 & 5 & 5 \\
\hline Vitamin mixture $^{1)}$ & 1 & 1 & 1 & 1 \\
\hline Mineral mixture ${ }^{2)}$ & 3.5 & 3.5 & 3.5 & 3.5 \\
\hline Choline bitartrate & 0.2 & 0.2 & 0.2 & 0.2 \\
\hline $\begin{array}{l}\text { Rubus coreanus } \\
\text { Miquel concentrate }\end{array}$ & 0 & 0 & 1 & 2 \\
\hline
\end{tabular}

1) Composition of the vitamin mixture (1.0\% in diet provided the following vitamins): $6 \mathrm{mg}$ thiamin $\mathrm{HCl}, 6 \mathrm{mg}$ iboflavin, $30 \mathrm{mg}$ nicotinic acid, $16 \mathrm{mg}$ calcium pantothenate, $2 \mathrm{mg}$ folic acid, $10 \mu \mathrm{g}$ cyanocobalamine, $0.2 \mathrm{mg}$ biotin, $4000 \mathrm{IU}$ vitamin A, $1000 \mathrm{IU}$ vitamin D, $50 \mathrm{IU}$ vitamin E, $50 \mu \mathrm{g}$ vitamin $\mathrm{K}$, and $7 \mathrm{mg}$ pyridoxine $\mathrm{HCl}$.

2) Composition of the mineral mixture [3.5\% in diet provided the following minerals (mg/kg diet)] : 5200 calcium (calcium phosphate, dibasic), 4000 phosphorus (calcium phosphate, dibasic), 1020 sodium (sodium chloride), 3600 potassium (potassium citrate, $\mathrm{H}_{2} \mathrm{O}$ ), 500 magnesium (magnesium oxide), 54 manganese (manganese carbonate), 35 iron (ferric chloride), 6 copper (cupric carbonate), 30 zinc (zinc carbonate), 0.2 iodine (potassium iodine), 0.1 selenium (sodium selenite, $5 \mathrm{H}_{2} \mathrm{O}$ ), 2.0 chrome (chrome potassium sulfate, $12 \mathrm{H}_{2} \mathrm{O}$ ), 1560 chloride (sodium chloride), and 1000 sulfate (potassium sulfate).

$\mathrm{CON}$ : Normal diet, $\mathrm{CCl}_{4}$ : $\mathrm{CCl}_{4}+$ Normal diet, $1 \% \mathrm{RCM} \mathrm{CCl}_{4}+1 \% \mathrm{RCM}$ diet, $2 \%$ $\mathrm{RCM}: \mathrm{CCl}_{4}+2 \% \mathrm{RCM}$ diet 
assay kit (Asan Pharmaceutical Co., Seoul). Low density lipoprotein-cholesterol (LDL-C) was calculated using Friedewald equation [LDL-C $=$ TC - HDL-C - $(\mathrm{TG} / 5)]$.

\section{Blood enzyme assays}

Serum AST and ALT were measured with a kit (Asan Phamaceutical Co., Seoul) using the Reitman-Frankel [19] method. Serum ALP was measured with a kit (Asan Phamaceutical Co., Seoul) using the Kind-King method and measuring absorbance with a UV-visible spectrophotometer.

\section{Preparation of liver tissues and liver index values}

Livers were extracted immediately after collecting blood and washed with cold saline. Excess moisture was removed with filter paper, and the liver weight was determined. Part of the liver was isolated for histopathologic examination. The remaining portion of the liver was quickly frozen at $-70^{\circ} \mathrm{C}$ with liquid nitrogen, and used for lipid peroxide and liver protein analyses. Liver index values were calculated with the formula liver weight / 100 g body weight.

\section{Evaluation of lipid peroxides and liver proteins}

Lipid peroxides in liver homogenates were measured with a thiobarbituric acid (TBA) method [20] using a standard 1,1,3,3,tetra ethoxypropane solution. Liver homogenates were diluted to $10 \%$ with cold $\mathrm{KCl}$ buffer, and $3 \mathrm{~mL}$ of $1 \%$ phosphoric acid was added to $0.5 \mathrm{~mL}$ of the diluted solution. Next, $1 \mathrm{~mL}$ of the TBA solution was added. The tubes containing the solution were covered with caps, stirred in a boiling water bath for 45 minutes, and cooled by immersion in ice water. N-butanol (4 $\mathrm{mL}$ ) was then added and the solution was centrifuged. The uppermost layer of n-butanol was collected and the absorbance was measured at $535 \mathrm{~nm}$ with a UV-visible spectrophotometer. The results are presented as $\mathrm{nM}$ of TBARS per $1 \mathrm{mg}$ of protein. To measure total hepatic protein levels, the method described by Lowry et al. [21] was used with bovine serum albumin standard protein solutions.

\section{Determination of Superoxide dismutase (SOD)}

The liver was homogenized in buffer containing $0.25 \mathrm{M}$ sucrose, $10 \mathrm{mM}$ Tris-HCL, and 1mM EDTA (pH7.4). The crude homogenate was centrifuged at $10,000 \times \mathrm{g}$ for 60 minutes at $4^{\circ} \mathrm{C}$ and the supernatant was used for SOD activity which was determined by using the SOD assay kit (Dojindo Laboratories, Kumamoto, Japan), according to the manufacturer's protocol.

\section{Live histopathology evaluation}

Paraformaldehyde-fixed liver specimens were dehydrated in a graded alcohol series. Following treatment with xylene, the specimens were embedded in paraffin blocks and cut into 4- $\mu \mathrm{m}$ thick slices with a microtome. The sections were placed on glass slides, stained with hematoxylin-eosin (HE), and examined with a light microscope.

\section{Statistical Analysis}

The mean and standard deviations for each group were calculated using the SAS version 9.1. Differences in body weight, liver weight, liver index, blood lipid levels, enzyme activity, and liver lipid peroxide levels were analyzed with a one-way ANOVA and then Duncan's multiple range test with a confidence level of $P<0.05$.

\section{Results}

Weight gain, liver weight, and liver index

Weight gain in the $\mathrm{CCl}_{4}, 1 \% \mathrm{RCM}$, and $2 \% \mathrm{RCM}$ groups decreased compared to the normal group (Table 2). Liver weight increased $10 \%$ in the $\mathrm{CCl}_{4}$ group compared to the normal group $(P<0.05)$. In contrast, liver weight decreased in the $1 \% \mathrm{RCM}$ and $2 \% \mathrm{RCM}$ groups relative to the $\mathrm{CCl}_{4}$ group. Liver index (LI) values decreased in the both of RCM group compared to the $\mathrm{CCl}_{4}$ group.

Table 2. Average weight gain, liver weight, and liver index (LI) of the experimental rats

\begin{tabular}{lccc}
\hline \multicolumn{1}{c}{ Group } & $\begin{array}{c}\text { Weight gain } \\
(\mathrm{g})\end{array}$ & $\begin{array}{c}\text { Liver weight } \\
(\mathrm{g})\end{array}$ & $\begin{array}{c}\mathrm{LI} \\
(\mathrm{g} / 100 \mathrm{~g} \text { body weight })\end{array}$ \\
\hline $\mathrm{CON}$ & $130.00 \pm 16.32^{\mathrm{a} 1)}$ & $8.40 \pm 1.05^{\mathrm{b} 2)}$ & $2.52 \pm 0.20^{\mathrm{b}}$ \\
$\mathrm{CCl}_{4}$ & $90.62 \pm 15.68^{\mathrm{b}}$ & $9.46 \pm 0.99^{\mathrm{a}}$ & $2.97 \pm 0.34^{\mathrm{a}}$ \\
$1 \% \mathrm{RCM}$ & $96.11 \pm 17.46^{\mathrm{b}}$ & $8.62 \pm 0.70^{\mathrm{ab}}$ & $2.63 \pm 0.18^{\mathrm{b}}$ \\
$2 \% \mathrm{RCM}$ & $99.37 \pm 23.51^{\mathrm{b}}$ & $7.92 \pm 0.94^{\mathrm{b}}$ & $2.48 \pm 0.25^{\mathrm{b}}$ \\
\hline
\end{tabular}

CON: Normal diet, $\mathrm{CCl}_{4}: \mathrm{CCl}_{4}+$ Normal diet, $1 \% \mathrm{RCM} \mathrm{CCl}_{4}+1 \% \mathrm{RCM}$ diet, $2 \%$ $\mathrm{RCM}: \mathrm{CCl}_{4}+2 \% \mathrm{RCM}$ diet

LI (Liver index values); liver weight / $100 \mathrm{~g}$ body weight.

1) Values represent the mean $\pm S D$

${ }^{2)}$ Mean values with different superscripts within a given column are significantly different $(P<0.05)$ according to Duncan's multiple range test.

Table 3. Serum lipid levels in the experimental rats

\begin{tabular}{lcccc}
\hline Group & $\begin{array}{c}\text { Triglycerides } \\
(\mathrm{mg} / \mathrm{dL})\end{array}$ & $\begin{array}{c}\text { Total cholesterol } \\
(\mathrm{mg} / \mathrm{dL})\end{array}$ & $\begin{array}{c}\mathrm{HDL}-\mathrm{C} \\
(\mathrm{mg} / \mathrm{dL})\end{array}$ & $\begin{array}{c}\mathrm{LDL}-\mathrm{C} \\
(\mathrm{mg} / \mathrm{dL})\end{array}$ \\
\hline $\mathrm{CON}$ & $56.66 \pm 21.31^{\text {ns } 1)}$ & $54.28 \pm 6.54^{\mathrm{ab} 2)}$ & $22.22 \pm 3.10^{\mathrm{ab}}$ & $25.97 \pm 10.18^{\text {ns }}$ \\
$\mathrm{CCl}_{4}$ & $65.63 \pm 32.43$ & $69.80 \pm 22.19^{\mathrm{a}}$ & $18.78 \pm 0.60^{\mathrm{b}}$ & $32.03 \pm 22.89$ \\
$1 \% \mathrm{RCM}$ & $49.85 \pm 13.08$ & $50.05 \pm 9.12^{\mathrm{b}}$ & $22.12 \pm 4.50^{\mathrm{ab}}$ & $23.77 \pm 16.11$ \\
$2 \% \mathrm{RCM}$ & $45.13 \pm 7.75$ & $42.33 \pm 15.08^{\mathrm{b}}$ & $27.10 \pm 6.37^{\mathrm{a}}$ & $16.74 \pm 11.51$ \\
\hline
\end{tabular}

CON: Normal diet, $\mathrm{CCl}_{4}$ : $\mathrm{CCl}_{4}+$ Normal diet, $1 \% \mathrm{RCM} \mathrm{CCl}_{4}+1 \% \mathrm{RCM}$ diet, $2 \%$ $\mathrm{RCM}: \mathrm{CCl}_{4}+2 \% \mathrm{RCM}$ diet

ns: not significant

1) Values represent the mean $\pm S D$

${ }^{2}$ Mean values with different superscripts within a given column are significantly different $(P<0.05)$ according to Duncan's multiple range test. 
Table 4. Serum biochemical indices of liver function for the experimental rats

\begin{tabular}{lccc}
\hline \multicolumn{1}{c}{ Group } & AST (IU/L) & ALT (IU/L) & ALP (IU/L) \\
\hline CON & $149.69 \pm 14.54^{\mathrm{b} 1)}$ & $16.49 \pm 4.93^{\mathrm{b} 2)}$ & $22.98 \pm 3.22^{\mathrm{b}}$ \\
$\mathrm{CCl}_{4}$ & $185.97 \pm 6.96^{\mathrm{a}}$ & $55.28 \pm 22.35^{\mathrm{a}}$ & $28.45 \pm 3.07^{\mathrm{a}}$ \\
$1 \% \mathrm{RCM}$ & $156.46 \pm 26.42^{\mathrm{b}}$ & $34.26 \pm 12.29^{\mathrm{b}}$ & $18.03 \pm 4.76^{\mathrm{c}}$ \\
$2 \% \mathrm{RCM}$ & $152.92 \pm 17.00^{\mathrm{b}}$ & $29.85 \pm 8.16^{\mathrm{b}}$ & $18.27 \pm 3.40^{\mathrm{c}}$
\end{tabular}

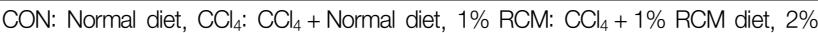
RCM: $\mathrm{CCl}_{4}+2 \%$ RCM diet, AST: aspartate amino transferase, ALT: alanine amino transferase, ALP: alkaline phosphatase

1) Values represent the mean $\pm \mathrm{SD}$

${ }^{2)}$ Mean values with different superscripts within a given column are significantly different $(P<0.05)$ according to Duncan's multiple range test.

Table 5. Hepatic TBARS levels in the experimental rats

\begin{tabular}{lc}
\multicolumn{1}{c}{ Group } & Liver TBARS $(\mathrm{nM} / \mathrm{mg}$ protein) \\
\hline $\mathrm{CON}$ & $1.25 \pm 0.36^{\mathrm{b} 1)}$ \\
$\mathrm{CCl}_{4}$ & $\left.1.73 \pm 0.37^{\mathrm{a} 2}\right)$ \\
$1 \% \mathrm{RCM}$ & $1.32 \pm 0.24^{\mathrm{b}}$ \\
$2 \% \mathrm{RCM}$ & $1.29 \pm 0.06^{\mathrm{b}}$ \\
\hline
\end{tabular}

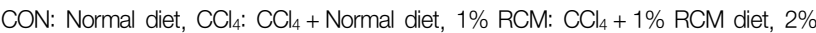
$\mathrm{RCM}: \mathrm{CCl}_{4}+2 \%$ RCM diet

1) Values represent the mean $\pm S D$

${ }^{2)}$ Mean values with different superscripts within a given column are significantly different $(P<0.05)$ according to Duncan's multiple range test.

Table 6. Hepatic SOD levels in the experimental rats

\begin{tabular}{lc}
\hline \multicolumn{1}{c}{ Group } & Liver SOD $(\mathrm{U} / \mathrm{mg}$ protein $)$ \\
\hline $\mathrm{CON}$ & $19.65 \pm 3.71^{\mathrm{a} 1)}$ \\
$\mathrm{CCl}_{4}$ & $12.87 \pm 1.28^{\mathrm{c} 2)}$ \\
$1 \% \mathrm{RCM}$ & $14.68 \pm 0.74^{\mathrm{bc}}$ \\
$2 \% \mathrm{RCM}$ & $16.0 . \pm 1.07^{\mathrm{b}}$ \\
\hline
\end{tabular}

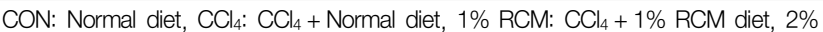
$\mathrm{RCM}: \mathrm{CCl}_{4}+2 \% \mathrm{RCM}$ diet

1) Values represent the mean $\pm \mathrm{SD}$

${ }^{2)}$ Mean values with different superscripts within a given column are significantly different $(P<0.05)$ according to Duncan's multiple range test.

\section{Blood lipid levels}

Blood lipid levels are shown in Table 3. The levels of triglycerides tended to decrease with RCM dietary supplementation, but this difference was not significant. Total blood cholesterol levels decreased in the $1 \%$ and $2 \%$ RCM groups compared to the $\mathrm{CCl}_{4}$ group $(P<0.05)$. The levels of HDL-C significantly increased in the $2 \% \mathrm{RCM}$ group compared to the $\mathrm{CCl}_{4}$ group $(P<0.05)$. There were no significant differences in LDL-C levels between the groups.

\section{Effect of RCM on AST, ALT, and ALP}

As shown in Table 4, treatment with $\mathrm{CCl}_{4}$ significantly increased the levels of AST (185.97 IU/L), ALT (55.28 IU/L), and ALP (28.45 IU/L) in serum compared to the control group (149.69 IU/L, $16.49 \mathrm{IU} / \mathrm{L}$, and 22.98 IU/L, respectively). Dietary supplementation with RCM significantly decreased the activities of AST, ALT, and ALP compared to $\mathrm{CCl}_{4}$-treated rats $(P<0.05)$.
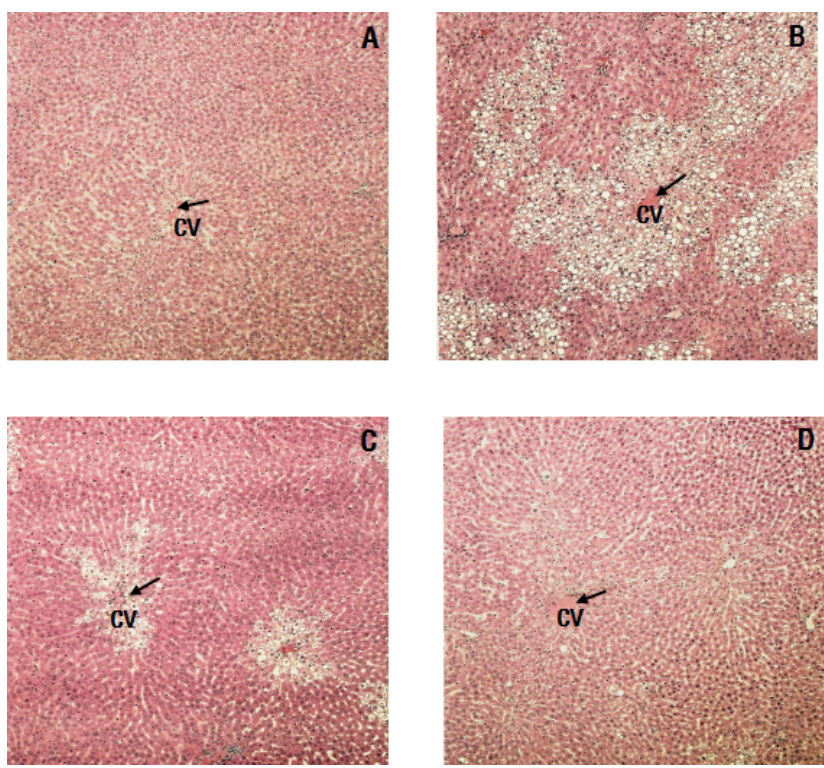

Fig. 1. Histopathological examination of liver tissues from the experimental rats (A) Control group, (B) $\mathrm{CCl}_{4}$ group, (C) $\mathrm{CCl}_{4}+1 \% \mathrm{RCM}$ group, (D) $\mathrm{CCl}_{4}+2 \% \mathrm{RCM}$ group, CV: central vein, Hematoxylin-eosin staining, 100× magnification

\section{Hepatic lipid peroxides}

The concentrations of liver lipid peroxides are shown in Table 5. Intraperitoneal injection of $\mathrm{CCl}_{4}$ increased lipid peroxide levels from $1.25 \mathrm{nM}$ to $1.73 \mathrm{nM}$ of TBARS/g. However, liver lipid peroxide concentrations decreased in the RCM-supplementation groups compared to the $\mathrm{CCl}_{4}$ group $(P<0.05)$. The levels of hepatic lipid peroxides observed in rats given the RCM extract were similar to those of the normal group.

\section{Hepatic SOD activities}

The activities of liver SOD are shown in Table 6. Treatment of $\mathrm{CCl}_{4}$ decreased SOD activity from $19.65 \mathrm{U} / \mathrm{mg}$ protein to $12.87 \mathrm{U} / \mathrm{mg}$ protein. In $2 \% \mathrm{RCM}$ supplementation groups, activity of SOD was increased compared to the $\mathrm{CCl}_{4}$ group $(P$ $<0.05$ ).

\section{Evaluation of liver histology}

As shown in Fig. 1, massive necrosis in the centrilobular area and degenerative changes were observed in livers from the $\mathrm{CCl}_{4}$ group. These hepatic changes decreased with administration of $\mathrm{RCM}$, and damages to the liver lobules around the portal vein were reduced.

\section{Discussion}

Phytochemicals, such as polyphenols and terpenes are believed to play a role as chemopreventive agents. The bioactive components of RCM have been identified various kinds of tannins, 
flavonoids, and triterpenoids. RCM has been used to help protect the liver, brighten the eyes, and alleviate diabetes' symptoms [9]. Furthermore, RCM has been reported to affect immune function and control weight [17]. However, research on the ability of RCM to help protect the liver and improve liver function is insufficient.

In the present study, we evaluated the hepatoprotective effects of RCM concentrates against liver injuries induced by $\mathrm{CCl}_{4}$ in rats. Administration of $\mathrm{CCl}_{4}$ induced liver necrosis, steatosis, and fibrosis caused by reactive oxygen species (ROS) and inflammation [22]. Administration of $\mathrm{CCl}_{4}$ also led to decreased body weight and increased liver weight in the rats. Increased liver weight caused by $\mathrm{CCl}_{4}$ might be attributed to augmented permeability of the liver cell membrane, cell edema, and lipid oxidation [23]. Lipid contents of normal liver cells are determined by a balance between lipid synthesis and utilization, and are increased in the liver damaged by $\mathrm{CCl}_{4}[24,25]$. The levels of total serum cholesterol in the $\mathrm{CCl}_{4}$ group in this study increased compared to the normal group. Additionally, administration of $\mathrm{CCl}_{4}$ not only elevated the activities of serum AST, ALT, and ALP but also the levels of hepatic TBARS which are products of lipid peroxide reactions, and increased by oxidative stress and free radical in cell [24,25]. Production of these lipid peroxides following $\mathrm{CCl}_{4}$ treatment might be induced by trichloromethyl free radicals and change the structure of liver cell membranes [26].

Damages to the liver by $\mathrm{CCl}_{4}$ were improved by dietary supplementation with RCM in this study. The hepatoprotective activity of RCM can be due to its anti-inflammatory effect demonstrated by increased hepatic SOD activity. The liver weight and LI returned to normal levels with RCM treatment. The blood levels of HDL-C increased while total serum cholesterol levels decreased following RCM dietary supplementation. Polyphenols in RCM exert beneficial effects on blood lipid levels, and have been reported to protect against cardiovascular disease [27,28].

In the presence of liver necrosis and the destruction of liver tissues by toxic agents, liver transaminases (AST and ALT) are released into blood and have been found to have high levels of activity [29]. ALP is also associated with conditions linked to the hepatic biliary tract. In our study, activities of AST, ALT, and ALP elevated by $\mathrm{CCl}_{4}$ exposure were decreased by the RCM concentrates. These results suggest that RCM might play an important role in the protective effects against $\mathrm{CCl}_{4}$-induced injury. RCM might be ameliorated in wrecked integrity of hepatic cell and infiltration of liver. RCM could be considered to be hepatoprotective by possibly improving liver function and restoring the activities of AST, ALT, and ALP in this study. Hepatic TBARS levels were markedly reduced and SOD levels were significantly increased by supplementation of the RCM concentrates in the present study. RCM contains phenols and cyannidin 3-glucoside. The effects of RCM on lipid peroxides and SOD observed in the present study may have been attributed to the antioxidant properties.
The histopathological examination performed in our study identified massive necrosis in hepatic centrilobular area and degenerative changes following $\mathrm{CCl}_{4}$ exposure that was improved by dietary supplementation with RCM concentrates. Indeed, the antioxidative potency of RCM can actually affect the recovery of liver structure in $\mathrm{CCl}_{4}$-induced liver Injuries. Histological examination demonstrated that RCM concentrates presented light hepatotoxicity effects on $\mathrm{CCl}_{4}$-induced Sprague-Dawley rats.

In conclusion, active compounds of RCM decreased the level of total cholesterol and hepatic damage in $\mathrm{CCl}_{4}$-treated SpragueDawley rats. Although further examination on the active compounds of RCM is needed, RCM concentrates have potent antioxidant activities that might protect the liver and improve the symptoms of liver injuries caused by $\mathrm{CCl}_{4}$ in rats.

\section{References}

1. Jun DW, Cho YK, Sohn JH, Lee CH, Kim SH, Eun JR. A study of the awareness of chronic liver diseases among Korean adults. Korean J Hepatol 2011;17:99-105.

2. Campos R, Garrido A, Guerra R, Valenzuela A. Silybin dihemisuccinate protects against glutathione depletion and lipid peroxidation induced by acetaminophen on rat liver. Planta Med 1989; 55:417-9.

3. Ip SP, Yiu HY, Ko KM. Differential effect of schisandrin B and dimethyl diphenyl bicarboxylate (DDB) on hepatic mitochondrial glutathione redox status in carbon tetrachloride intoxicated mice. Mol Cell Biochem 2000;205:111-4.

4. Kwak CS, Kim MY, Lee MS. Antioxidative effect of plant food mixtures in rat fed on high fat-high cholesterol diet. Korean J Nutr 2005;38:352-63.

5. Seeram NP, Aviram M, Zhang Y, Henning SM, Feng L, Dreher M, Heber D. Comparison of antioxidant potency of commonly consumed polyphenol-rich beverages in the United States. J Agric Food Chem 2008;56:1415-22.

6. Fazio A, Plastina P, Meijerink J, Witkamp RF, Gabriele B. Comparative analyses of seeds of wild fruits of Rubus and Sambucus species from Southern Italy: fatty acid composition of the oil, total phenolic content, antioxidant and anti-inflammatory properties of the methanolic extracts. Food Chem 2013;140: 817-24.

7. Jeon SK, Lee JW, Lee IS. Effect of antioxidant activity and induction of DNA damage of human gastric cancer cell by Rubus coreanus Miquel. J Life Sci 2007;17:1723-8.

8. Lee JW, Do JH. Chemical compounds and volatile flavor of Rubus coreanum. Korean J Food Nutr 2000;13:453-9.

9. Cha HS, Park MS, Park KM. Physiological activities of Rubus coreanus Miquel. Korean J Food Sci Technol 2001;33:409-15.

10. Lee JE, Park E, Lee JE, Auh JH, Choi HK, Lee J, Cho S, Kim JH. Effects of a Rubus coreanus Miquel supplement on plasma antioxidant capacity in healthy Korean men. Nutr Res Pract 2011;5:429-34

11. Lim JW, Hwang HJ, Shin CS. Polyphenol compounds and anti-inflammatory activities of Korean black raspberry (Rubus coreanus Miquel) wines produced from juice supplemented with pulp and seed. J Agric Food Chem 2012;60:5121-7.

12. $\mathrm{Ku} \mathrm{CS}$, Mun SP. Antioxidant activities of ethanol extracts from 
seeds in fresh Bokbunja (Rubus coreanus Miq.) and wine processing waste. Bioresour Technol 2008;99:4503-9.

13. Chou WH, Oinaka T, Kanamaru F, Mizutani K, Chen FH, Tanaka O. Diterpene glycosides from leaves of Chinese Rubus chingii and fruits of R. suavissimus, and identification of the source plant of the Chinese folk medicine "fu-pen-zi". Chem Pharm Bull (Tokyo) 1987;35:3021-4.

14. Hattori M, Kuo KP, Shu YZ, Tezuka Y, Kikuchi T, Namba T. A triterpene from the fruits of Rubus chingii. Phytochemistry 1988;27:3975-6.

15. Ohtani K, Miyajima C, Takahasi T, Kasai R, Tanaka O, Hahn DR, Naruhashi N. A dimeric triterpene-glycoside fromRubus coreanus. Phytochemistry 1990;29:3275-80.

16. Lim JD, Yu CY, Kim MJ, Yun SJ, Lee SJ, Kim NY, Chung IM. Comparision of SOD activity and phenolic compound contents in various Korean medicinal plants. Korean J Med Crop Sci 2004;12:191-202.

17. Kwon KH, Cha WS, Kim DC, Shin HJ. A research and application of active ingredients in Bokbunja (Rubus coreanus Miquel). Korean J Biotechnol Bioeng 2006;21:405-9.

18. Kim HS, Chyun JH. Effects of dietary protein level on catecholamine concentration of laparotomized rats. Korean J Nutr 1992;25:248-55.

19. Reitman S, Frankel S. A colorimetric method for the determination of serum glutamic oxalacetic and glutamic pyruvic transaminases. Am J Clin Pathol 1957;28:56-63.

20. Wada M, Nagano M, Kido H, Ikeda R, Kuroda N, Nakashima K. Suitability of TBA method for the evaluation of the oxidative effect of non-water-soluble and water-soluble rosemary extracts.
J Oleo Sci 2011;60:579-84.

21. Peterson GL. Review of the Folin phenol protein quantitation method of Lowry, Rosebrough, Farr and Randall. Anal Biochem 1979;100:201-20.

22. Basu S. Carbon tetrachloride-induced lipid peroxidation: eicosanoid formation and their regulation by antioxidant nutrients. Toxicology 2003;189:113-27.

23. Sicilia T, Mally A, Schauer U, Pähler A, Völkel W. LC-MS/MS methods for the detection of isoprostanes (iPF2alpha-III and 8,12-iso-iPF2alpha-VI) as biomarkers of CCl4-induced oxidative damage to hepatic tissue. J Chromatogr B Analyt Technol Biomed Life Sci 2008;861:48-55.

24. Weber LW, Boll M, Stampfl A. Hepatotoxicity and mechanism of action of haloalkanes: carbon tetrachloride as a toxicological model. Crit Rev Toxicol 2003;33:105-36.

25. Mourelle M, Meza MA. CCl4-induced lipoperoxidation triggers a lethal defect in the liver plasma membranes. J Appl Toxicol 1990;10:23-7.

26. Hsiao G, Shen MY, Lin KH, Lan MH, Wu LY, Chou DS, Lin $\mathrm{CH}, \mathrm{Su} \mathrm{CH}$, Sheu JR. Antioxidative and hepatoprotective effects of Antrodia camphorata extract. J Agric Food Chem 2003;51: 3302-8.

27. Basarkar PW, Nath N. Cholesterol lowering action of vitamin P-like compounds in rats. Indian J Exp Biol 1981;19:787-9.

28. Matsumoto N, Okushio K, Hara Y. Effect of black tea polyphenols on plasma lipids in cholesterol-fed rats. J Nutr Sci Vitaminol (Tokyo) 1998;44:337-42.

29. Giannini EG, Testa R, Savarino V. Liver enzyme alteration: a guide for clinicians. CMAJ 2005;172:367-79. 